\title{
Valorização docente na (re)construção da Identidade dos profissionais do ensino superior em Angola
}

\author{
Arão Chilulo Cutatela \\ Alfredo Maria de Jesus Paulo \\ Luís Alexandre da Fonseca Tinoca \\ Escola Superior Pedagógica do Bié (Angola) \\ Instituto de Educação da Universidade de Lisboa (Portugal)
}

\section{Resumo}

$\bigcirc$ presente artigo tem como finalidade refletir em torno da valorização docente, na (re)construção da identidade dos profissionais do Ensino Superior (ES) em Angola. $\bigcirc$ estudo faz uso de uma abordagem qualitativa, inserida no paradigma interpretativo, recorrendo à análise de discurso e de conteúdo, articulada aos documentos normativos e estudos realizados por diversos investigadores sobre a temática em diferentes contextos educativos e sociais de modo geral, e na realidade dos docentes e vivência dos autores no Ensino Superior em Angola em particular, enquanto campo da atuação de dois dos autores. $\bigcirc$ objetivo principal do estudo é articular as orientações expressas nos documentos normativos e a importância que os diferentes autores atribuem a esta temática, com a análise da realidade angolana. As conclusões rementem para uma compreensão da temática a partir de uma visão unilateral reforçando a necessidade valorizar profissionalmente os docentes do Ensino Superior em Angola.

Palavras-chave: Ensino Superior, Identidade, Profissão docente, (Re)construção, valorização

\section{Teacher appreciation in the (re)construction of the identity of Higher Education professionals in Angola}

\section{Abstract}

This article aims to reflect about the appreciation of professors, and the (re)construction of the identity of Higher Education (HE) professionals in Angola. The study uses a qualitative approach, framed by an interpretative paradigm, using discourse and content analysis, articulated with normative documents and studies carried out by several researchers on this subject in different educational and social contexts in general, and particularly in the case of Angola, where two of the authors came from. The main goal of the study is to articulate the guidelines expressed in the national normative documents and the importance that different authors attach to this topic, with the analysis of the Angolan reality. Conclusions point to an understanding of this topic from an unilateral perspective, reinforcing the need to professionally value Higher Education professors in Angola.

Keywords: Higher Education, Identity, (Re)construction, Teaching profession, valorization 


\section{Valorización de los docentes en la (re)construcción de la identidad de los profesionales de la Enseñanza Superior en Angola}

\section{Resumen}

El presente artículo tiene como finalidad reflexionar en torno a la valorización docente en la (re)construcción de la identidad de los profesionales de Enseñanza Superior (ES) en Angola. El estudio emplea un abordaje cualitativo, inserto en el paradigma interpretativo, recurriendo a análisis de discurso y de contenido, articulado a los documentos normativos y estudios realizados por diversos investigadores sobre esta temática en diferentes contextos educativos y sociales de modo general, y en la realidad de los docentes y la vivencia de los autores en la Enseñanza Superior en Angola en particular, en cuanto campo de trabajo de dos de los autores. El objetivo principal del estudio es articular las orientaciones expresadas en los documentos normativos y la importancia que los diferentes autores atribuyen a esta temática, con el análisis de la realidad angoleña. Las conclusiones remiten a una comprensión de la temática a partir de una visión unilateral, reforzando la necesidad de valorizar profesionalmente a los docentes de Enseñanza Superior en Angola.

Palabras clave: Enseñanza Superior, identidade, (re)construcción, profesión docente, valorización.

\section{Introdução}

presente artigo tem como finalidade refletir em torno da valorização docente, na construção da identidade dos profissionais do Ensino Superior em Angola. O texto aponta para uma compreensão sobre a temática, abordada a partir de uma visão diacrónica de autores, e diversos estudos realizados a nível internacional tais como: Lawn (2000); Teodoro (2004); Vargas (2008); Nóvoa (2009; 2017); Moreira (2010); Cardoso (2013); Melo (2016); Teixeira, Batista e Graça, (2017), entre outros.

Em Angola, esta temática tem suscitado diversos debates no seio da classe dos profissionais da educação e da classe política. No entanto, escasseiam as publicações sobre esta problemática. Genericamente apontam-se os estudos desenvolvidos por Buza e Gonçalves (2007); Cardoso e Flores (2009); Buza e Buza (2015); Raul (2015); Silva e Silva (2015); Simões, Sambo, Ferreira e Fresta (2016); Cassule e Simões (2018) entre outros, destacando-se com maior profundidade a Profissão Docente no Ensino Superior (ES), seus processos evolutivos e entravés, sobressaindo a necessidade da construção da ldentidade Profissional do Docente do ES e suas representações (RAUL, 2015; CASSULE; SIMÕES, 20181. 
Desta forma, reconhecemos com naturalidade que a questão da identidade profissional é atual e necessária em vários ambientes sociais, culturais e profissionais, particularmente no contexto Angolano. Neste seguimento, o presente estudo é orientado pela seguinte questão de investigação: Qual é a importância da valorização docente na construção da identidade dos profissionais do Ensino Superior em Angola? Consideramos direcionar o nosso entendimento a um objetivo: Valorizar a Profissão Docente na construção da identidade dos profissionais do Ensino Superior em Angola.

\section{A Profissão Docente no Ensino Superior. Resenha contextual em Angola}

Ser professor é uma profissão única, insubstituivel. É ela que torna as outras profissões possíveis. Assim mais do que uma profissão, ser professor é uma carreira cheia de desafios, que se vão sucedendo, a cada dia, na medida em que a própria sociedade está em constante mutação (CARDOSO, 2013, p. 37).

A constituição do ser professor, isto é, de sua identidade, perpassa por diversas questões que vão desde a sua socialização primária, enquanto aluno da escola, seguindo para a formação inicial em cursos de licenciatura, até tornar-se professor de fato, ficando em formação permanente (IZA, BENITES; NETO; CYRINO; ELISANGELA; ARNOSTI; SANCHES NETO, 2014). A docência "[...] é, ao mesmo tempo, uma atividade intelectual e uma atividade técnica; uma atividade moral e uma atividade relacional" (FORMOSINHO, 2009, p. 911.

A Profissão Docente é um dos ofícios mais antigos e importantes do mundo e sempre esteve presente em nossa vida formativa escolar e seu campo de atuação vai sofrendo mudanças significativas de época em época (MELO, 2016), facto que a torna por sua natureza numa atividade profissional mais complexa (MACHADO; FORMOSINHO, 2009). Nunca existiram épocas em que fosse facíl exercê-la (ESTRELA, 2010). Não é em vão, que os países mais desenvolvidos são aqueles que melhor capital humano possuem (CARDOSO, 2013 ) frutos desta componente profissional. 
conceito de profissão assume várias conotações tendo em conta os diferentes aspectos caracterizadores da Profissão Docente (MESQUITA, 2010). A autora, definine a Profissão Docente como um "[...] conjunto de saberes profissionais inerentes e necessários ao seu exercício. Estes saberes são de natureza diversa e são eles mesmos os elementos caracterizadores da especificidade profissional dos professores" (MESQUITA, 2010, p. 7).

○ cenário atual da educação angolana a sua génese, foi marcada por fortes crises políticas. Dois anos após a independência, em Angola, desenhou-se a primeira reforma educativa que entraria em vigor em 1978 (SILVA; SILVA, 20151 , com a aprovação de um novo Sistema Nacional de Educação e Ensino (CARDOSO; FLORES, 2009), que caracterizou-se essencialmente por uma maior oportunidade de acesso a educação e a continuação dos estudos, o alargamento da gratuitidade e aperfeiçoamento permanente do pessoal docente (MED, 2010 ; CARDOSO; FLORES, 2009; SILVA; SILVA, 2015).

Este processo ocorreu tardiamente porque, as condições que levaram o surgimento do ES através da única instituição em Angola, não tinham sido das melhores, por estarem diretamente relacionados com a necessidade de atender os descendentes da elite no momento, e favorecer a formação para 4 alguns poucos que se destacavam e que serviam de mão-de-obra para a administração da época (BUZA; BUZA, 2015).

A Profissão Docente era exercida para a favorecer as políticas socioeconómicas e os monopólios do regime da época e a identidade profissional docente por ter características fincadas na construção histórica dos sujeitos acompanhou a evolução educativa e determinou os modos de ser e de estar na profissão dando significado social ao docente da época.

Com o surgimento da Paz em Angola e na expectativa de atenuar os graves problemas da educação causados pelo fenómeno colonial e pela guerra civil que assolou o país durante três décadas, se realiza a segunda reforma educacional. Nesse curto período, o governo vem efetuando políticas públicas em busca de saídas satisfatórias para a educação e para outros setores da vida pública. Porém, é necessário admitir que os resultados ainda se encontram em passos tímidos pelo próprio contexto histórico político de turbulências de aproximadamente cinco séculos e trinta décadas, considerando o período colonial (BUZA; GONÇALVES, 2007). 
A Profissão Docente e a importância do Ensino Superior (ES) para o desenvolvimento dos países e dos povos são amplamente reconhecidas. Seu progresso nas sociedades é inegável, tendo como base o seu esperado impacto positivo na produção de riquezas, o reforço das instituições, e na melhoria da qualidade de vida das pessoas (SIMÕES, SAMBO, FERREIRA; FRESTA, 2016).

O surgimento desta instituição em Angola, tem despertado nos últimos tempos, o interesse de muitos estudiosos, dedicando-he pequenas referências, capítulos, artigos em obras académicas e/ ou livros inteiros, porém, nem sempre coincidentes com a ordem cronológica e o tipo de fatos históricos em que se fundamenta a narrativa de cada um ou de um grupo de autores (IRMAPANZO, 2018).

Angola, em via de desenvolvimento, fruto da paz alcançada em 2002, fator decisivo do crescimento notório do ES nos últimos anos deu continuidade às mudanças educativas iniciadas em 1975, após a independência. Essas mudanças sugerem a introdução de novos materiais, de novas metodologias e, consequentemente, de um novo perfil do docente (SIIVA; SILVA, 2015) e da sua profissão, que precisa ganhar autonomia, maior credibilidade e o devido respeito que merece.

Com a expansão massiva das Instituições de Ensino Superior (IES) em toda a extensão do país (ANGOLA, 2009), os desafios deste sector em Angola indiciam um longo caminho a percorrer para a consolidação do sistema e a sua integração nos espaços geopolíticos de ensino e de pesquisa (SIMÕES, SAMBO, FERREIRA; FRESTA, 2016) constituintes necessários para impulsionar a Profissão Docente e a (re)construção da identidade de muitos profissionais que durante muito tempo, estiveram grudados as obstinações e ao processo de gestão rígida e parcial de pequenas elites, de gestores e políiticos.

Perante esse progresso inicial da expansão universitária, em algumas àreas, levantava-se o problema respeitante a um corpo docente autonomo que corresponda as exigências do momento (KANDINGI, 2016).

Tendo em conta que a melhoria da qualidade do ensino e de investigação para a (re)construção da identidade destes profissionais passa pela aposta na qualidade de um corpo docente diferenciado, com mestres e doutores empenhados e dedicados à produção científica e à excelência académica, Angola deve criar condições para atração de quadros de alto nível e promover 
a estabilidade do corpo docente e garantindo o seu progresso na carreira docente universitária (KANDINGI, 2016).

Portanto, essas condições apesar de maioritariamente estarem refletidas nos documentos normativos, devem merecer maior atenção por parte do Estado Angolano, e serem enquadradas de forma democrática nas políticas públicas que vão operando-se no País e que sejam tidas em conta deste a organização dos pressupostos legais, até a credibilização e valorização dos docentes. Aspeto imperioso para que o professor cumpra efetivamente com as funções profissionais docentes: docente metodológica, investigativa e educativa.

Por isso, esta comunicação, é de capital importância a medida em que reflete-se no novo quadro constitucional e dos novos desafios de desenvolvimento que se colocam na atualidade, traduzidos em diferentes planos e programas estratégicos de desenvolvimento a fim de garantir a inserção de Angola no contexto regional e internacional (ANGOLA, 2016).

Em Angola, com a promulgação do Decreto-Lei n. ${ }^{\circ} 17 / 16$, de 7 de Outubro, Lei de Bases do Sistema de Educação e Ensino (ANGOLA, 2016), e do Decreto-Lei no 191/18 de 8 de agosto 2018, do Estatuto da Carreira Docente do Ensino Superior (ANGOLA, 2018), são notaveis, as exigências políticas plasmadas nestes documentos que o estado Angolano impõem para o Ensino Superior (ES) e Profissão Docente na melhoria da qualidade de ensino, aspetos incompativeis com o desenvolvimento pessoal dos docentes e seus modos de desenvolvimento profissional, fatores que também condicionam a Profissão Docente e dificultam a (re)construção da identidade profissional.

De referir que, o desenvolvimento pessoal e profissional da Profissão Docente em Angola, estão enraizados no processo de desvalorização destes profissionais que durante muito tempo tiveram que passar, desde a elevada carga horária principalmente em docentes com o grau académico e categoria docente mais baixas (assistentes estagiários, assistentes), níveis salariais baixos, falta de atualização na carreira e nas categorias docentes, falta de abertura e imparcialidade na selecção dos docentes que participam de formações contínuas e outras formações, difíceis e precárias condições de trabalhos, intensificação do trabalho docente por via de lógicas de burocratização e de controlo pelo gestores. 
Em Angola, "[...] alguns docentes enfrentam no desempenho das suas funções dificuldades tais como falta de motivação e falta de formação contínua e pedagógica" (RAUL, 2015 , p. 5), assim como as debilidades formativas obitidas ao longo da formação incial que muitos tiveram de passar, aliados a falta de remuneração de subsídeos a que têm direito, que condicionam o seu desenvolvimento profissional e inibem a (re)construção da sua identidade profisssional.

Associados a estes, está a carência de docentes e as condições que as instituiç̃ões apresentavam e algumas apresentam no momento, este subsistema de ensino, viu-se submetido em um tipo de gestão que não se ajustava com uma academia. Tal foi o forte pender políitico e de orientação mais ideológica do que académica e científica (BUZA; BUZA, 2015).

Recentemente a Ministra do Ensino Superior, Ciência Tecnologia e Inovação de Angola, Professora Doutora Maria do Rosário Bragança Sambo, ao análisar os programas da SADC e seu envolvimento no Ministério do Ensino Superior Ciência Tecnologia e Inovação (MESCTI, 2018), no $2^{\circ}$ Conselho Nacional do Ensino Superior, chamou atenção para alguns achados preliminares no respeitante as dificuldades do Ensino Superior em Angola, destacam-se a proliferação das Instituições do Ensino Superior e a má qualidade dos formados, a inexistência de qualificações e habilitações literárias formais e a escassez de quadros com experiência profissional (MINISTÉRIO DO ENSINO SUPERIOR, CIÊNCIA, TECNOLOGIA E INOVAÇÃO, 2018).

Estudos realizados por, Simões, Sambo, Ferreira e Fresta (2016) sobre - ES no contexto Africano, referindo-se sobre os "desafios e oportunidades" apontam os seguintes fatores que dificultam a Profissão Docente em Angola:

a) A escassez e pouca diferenciação do corpo docente no Ensino Superior, assim como, a predominância nas universidades de docentes maioritariamente com o grau académico de Licenciado, face ao exíguo número de cursos de Mestrado e, sobretudo, de Doutoramento em Angola.

c) As inadequadas condições de trabalho e a falta de incentivos para o ensino e a pesquisa tendem a desmobilizar e desmotivar os quadros mais capazes e mais qualificados (MOHAMEDBHAI apud SIMÕES, SAMBO, FERREIRA; FRESTA, 2016).

d) Falta de financiamento por parte do Estado que premeie o mérito aos docentes com maior produtividade para a promoção da qualidade. 

exercício da pesquisa.

e) $\bigcirc$ insuficiente número de quadros à partida capacitados para o

f) A fraca participação, disponibilidade e dedicação dos docentes no sistema de Ciência, Tecnologia e Inovação;

g) Falta de exercício de pesquisa nas Instituições de Ensino Superior, os poucos que se têm realizado, em geral estão associados a iniciativas individuais ou de grupo, esporádicas;

h) Fraca qualidade na produção de algumas Monografias, Dissertações, e outros documentos e à ausência de financiamentos e incentivos para a investigação (SIMÕES, SAMBO, FERREIRA; FRESTA, 2016).

Os aspetos referidos, mostram que a Profissão Docente no Enino Superior, precisa com urgência traçar novos rumos, fatos que começam a ser notabilizados com a atualização da carreira docente e o aumento salarial embora que insuficientes face a atual conjuntura do País e assegurar as formações continuadas dos docentes aspetos que contribuem para a (re)construção da identidade profissional, como se perspetiva na Plano Nacional de Formação de Quadros (PNFQ, 2012 ); Lei de Bases do Sistema de Educação e Ensino (ANGOLA, 2016); Estatuto da Carreira Docente do Ensino Superior (ANGOLA, 2018) e o Plano Nacional de Desenvolvimento (PND, 20 18).

No Plano Nacional de Desenvolvimento (2018) quanto ao Ensino Superior se objetiva: (i) melhorar a rede de Instituições do Ensino Superior; (ii) aumentar os cursos e os graduados; (iii) aumentar a oferta de pós-graduações e melhorar a qualidade do ensino ministrado com o reforço da qualificação de mestres e doutores e melhorar a sua condição de trabalho e salarial; (iv) recrutar para a docência os melhores candidatos de entre os que possuem qualificação profissional; (v) atrair e reter os docentes mais bem preparados e com bom desempenho; (vi) proporcionar aos docentes em serviço oportunidades de desenvolvimento de competências profissionais. Entretanto Nóvoa refere:

A educação vive um tempo de grandes incertezas e de muitas perplexidades. Sentimos a necessidade da mudança, mas nem sempre conseguimos definir-the o rumo. Há um excesso de discursos, redundantes e repetitivos, que se traduz numa pobreza de práticas (NÓVOA, 2009, p. 2). 
Face a importância de se repensar na melhoria da Profissão Docente em Angola, é fundamental que as situações, e condições perspetivadas em prol desta profissão expressos nos regulamentos e documentos normativos enunciados, possam repercutir na sua valorização para (re)construção das identidades dos profissionais do Ensino Superior em Angola.

\section{A (re)construção da Identidade Profissional Docente}

A identidade profissional é um lugar de lutas e conflitos, um espaço no qual se constroem e reconstroem modos de ser e de estar na profissão (MOREIRA, 2010). Para Galindo (2004) a identidade é um processo de (re) construção de sujeitos enquanto profissionais. Ou seja, é um processo de (re)|construção social de um sujeito historicamente situado com base na sua significação profissional, de suas tradições e também de suas contradições (IZA; BENITES; NETO; CYRINO; ELISANGELA; ARNOSTI SANCHES NETO, 2014).

Este conceito representa uma marca que distingue o professor de outro funcionário, que se fundamenta na natureza específica da atividade exercida (a ação de ensinar), o saber requerido para a exercer, o poder de decisão sobre a ação, e ainda o nível de reflexividade sobre a ação que permite modificá-la (ROLDÃO, 2007).

Para Raul (2015), a (re)construção da identidade profissional docente é um processo complexo e inacabado, em que os professores vão consolidando saberes, gestos, rotinas, experiências e posturas, possibilitando-thes o exercício da sua atividade. Para Teixeira, Batista e Graça (2017), a identidade profissional é um processo dinâmico e evolutivo, (re)construído em interação que congrega duas dimensões: a individual e a coletiva.

Neste processo, a identidade individual contempla duas vertentes: a pessoal e à interação que o docente estabelece com os outros através da relação sujeito-objeto. A dimensão coletiva envolve a partilha de significados e de representações sociais no interior dos membros onde se estabelecem práticas comunicacionais favoráveis à (re)construção durante a formação.

Porém dentro da dimensão individual, coletiva e social a identidade docente simboliza também o sistema educativo e a nação que o criou, o que 
contribui para que o professor se identifique, se (re)constroe e contribua para a sua profissão (BUZA; GONÇALVES, 2007).

Moreira (2010), considera que na (re)construção da identidade profissional docente há três dimensões fundamentais: o desenvolvimento pessoal; o desenvolvimento profissional e o desenvolvimento Institucional.

Na prática, os professores, ao manifestarem suas motivações ao exercício docente, revelam suas subjetividades para o exercício da função. Apesar do compromisso social o "Eu" joga um papel preponderante para a (re)construção da identidade, que conta com as emoções diante das inquietações vividas, colocando-se na condição de eterno aprendiz para dar conta da responsabilidade assumida (BUZA; GONÇALVES 2007).

Na atualidade estudar sobre a (re)construção da identidade dos profissionais no contexto docente em Angola é também, identificar novas perspetivas de desenvolvimento pessoal e institucional da garantia de formação acente na mudança de novos paradigmas educativos e sociais do exercício da profissão, para melhorar a qualidade deste nível de ensino.

Durante vários momentos das vivências dos docentes em Angola a (re)construção da sua identidade profissional esteve maioritariamente sob o arbitrário do Estado e das suas instituições, através dos seus regulamentos, serviços, encontros políticos, discursos públicos, programas de formação, intervenções na média, etc. . tornou-se assim numa componente essencial do sistema, fabricada para gerir problemas de ordem pública e de regulamentação. A identidade foi "produzida" através de um discurso que simultaneamente, explica e constrói o sistema (LAWN, 2000).

Em Angola durante um tempo recente decorreu um processo de desvalorização profissional dos docentes e da eventual crise que parece ainda ser evidente nos dias atuais que, afirmar a identidade profissional pode contribuir para mudar este quadro e buscar melhores condições de trabalho para essa categoria profissional (BUZA; GONÇALVES, 2007).

Entedemos, que a qualidade da educação genericamene as suas próticas e de ensino, podem ser alcançadas pelos processos de desenvolvimento pessoal, profissional e do institucional, assim como da (re)construção da identidade docente. $\bigcirc$ desenvolvimento profissional é 
[...] aquele processo que envolve todas as experências expontâneas de aprendizagem e das atividades conscientes planificadas, realizadas para o benefício, direto ou indireto, do docente, do grupo ou da escola, e que contribuem, através destes, para a qualidade da educação na sala de aulas (DAY, 1999, p. 20).

Esta definição foi analisada neste contexto do estudo por ser abragente ao exercíco docente e por caraterizar o desenvolvimento profissional numa perspetiva de aprendizagem permanante do docente com vista a (re)construção da identidade profissional, que, em certa medida, o seu alcançe depende dos desafios impostos pelas Instituições de Ensino Superior em Angola.

Angola a (re)construção da identidade profissional do docente, não deve-se refletir apenas como uma "comunidade imaginada» da nação (não se pode iludir com boas palavras, políticas a sociedade sem o docente) mais deve tomar um rumo de momentos e desenvolvimento pessoal, profissional e institucional de que está é crucial para o estabelecimento ou reformulação dos seus objetivos económicos, sociais e educativos, tais como se encontram definidos pelo Estado (LAWN, 2000).

Para isso, a identidade profissional do docente deve: (i) ajustar-se à imagem do próprio projecto educativo da nação; (ii) permitir numa sociedade democrática beneficiar eficazmente a Profissão Docente e a criação, através de discurso oficial, da identidade do próprio docente; (iii) ser flexível, no interior de sistemas políticos e no conhecimento universitário (LAWN, 2000).

\section{Fatores que conduzem a valorização da (re)construção da Identidade Profissional Docente}

A (re)contrução da identidante profissioal docente como já foi referido, é constituída por meio de um processo dinâmico, em relação direta com o contexto social no qual está inserida, a pessoa e a instituição.

Não há um único fator que sozinho explique a valorização da Profissão Docente, há evidências de que ela está associada a uma soma de variáveis intervenientes que culminam na atual situação do desprestígio dessa profissão. Apesar de existirem leis que visem à melhoria do Ensino Superior, a maioria não há punição, deixando brecha para não efetivação dos benefícios em prol do Docente. Enquanto as políticas não efetivarem as leis, e enquanto a 
sociedade continuar mostrando descaso com estes profissionais, os mesmos não serão valorizados (MELO 2016, p. 11).

Iza; Benites; Neto; Cyrino; Elisangela; Arnosti; Sanches Neto (2014) consideram que os processos que conduzem a valorização docente na (re) construção da identidade docente não dependem apenas de fatores externos - como dos cursos de formação, dos formadores, dos currículos, etc., também são influenciados por fatores internos à própria pessoa, como, por exemplo, uma tomada de consciência de seu papel.

Porém, atualmente, muito se discute quando os docentes são devalorizados, tanto por parte do governo e seus governantes, como pela sociedade em geral (DETOMINI; MARIOTINI, 2017). Certamente a desvalorização profissional causa mal-estar e desmotivação no seio dos docentes, como refere Juses (1998 apud JESUS):

Não osbtante o mal-estar docente tem muito a ver com o contexto ou ambiente de trabalho do professor, sendo necessário introduzir diversas alterações no plano da formação e no plano sóciopolíitico, este problema também depende muito dos prórios professores, pois uns realizam-se na profissão e outros não (JESUS, 2004, p. 81 ).

A desmotivação dos professores é um dos indicadores do mal-estar docente na atualidade. Este conceito integra diversos indicadores, como o empenho profissional, o desejo de abandono da profissão docente, podendo, em sistuação de maior gravidade, traduzir-se em estados de exautão e até depressão (ESTEVES, 1992 citado por JESUS, 2004).

Nóvoa (1999) considera que os professores não são valorizados de forma íntegra e digna: nosso salário, muitas vezes, não serve nem para o sustento; nossa função é múltipla; as regras para entrada no curso de formação de professores são inadequadas; a formação inicial e continuada são muitas da vezes, ineficazes.

Os professores, há muito tempo, vêm sofrendo de uma situação de uma situação de mal-estar na profissão, que causa desmotivação pessoal com a docência, abandono, insatisfação, indisposição, desvestimento e ausência de reflexão crítica, entre outros sintomas que demonstram uma autodepreciação do professor. Esta situação abarca a crise da profissão docente, vem sendo bastante analisada 
e discutida pelos teóricos contemporâneos (NOVOA, 1999, p. 12).

Melo (2016) por exemplo, considera que existem três fatores que conduzem a valorização da Profissão Docente e consequantemente a (re) construção da identidade profissional: formação, condições de trabalho e remuneração.

Os fatores apontados devem ser (re)construidos permanentemente nas vivências da Profissão Docente pois, ao contrário podem conduzir a desvalorização o que em certa medida desprofissionaliza o professor.

Segundo Nóvoa (2017), a desprofissionalização docente manifesta-se de maneiras muito distintas, incluindo níveis salariais baixos e difíceis condições nas escolas, bem como processos de intensificação do trabalho docente por via de lógicas de burocratização e de controlo.

$\bigcirc$ autor considera ainda que é importante e pertinente recuperar o conceito de profissão numa era marcada pela "crise das profissões", por profissões híbridas e por novas formas de relação ao trabalho. A razão é simples. Nas últimas décadas tem havido uma diluição da profissionalidade docente, devido a duas razões principais (NÓVOA, 2017): (i) a degradação das condições de vida e de trabalho; (ii) a proliferação de discursos que descaracterizam a profissão docente.

Em Angola o desenvolvimento profissional docente foi durante muito tempo visto, numa perspectiva mais ideológica e de discurso institucional que na dimensão de resposta institucional. O discurso ideológico centrado no slogan "Ensino Superior de qualidade", não está a ser suficiente para buscar a convergência entre a regulação os processos sócioorganizacionais, porque a centralidade no positivismo premeia a criatividade construtivista do ambiente organizacional (MANUEL, 2016).

Portanto, a desvalorização da Profissão Docente é uma realidade é muitos contextos educativos e Angola não é excessão, apesar de existirem leis que visem à melhoria da Profissão Docente no Ensino Superior, não se cumprem, mesmo assim, os professores estão presentes em todos os discursos sobre a educação. Por uma ou por outra razão, fala-se sempre deles. Mas muitas vezes está-lhes reservado o "lugar do morto" (NÓVOA, 1999). 
Importa ainda referir que em Angola por exemplo o fator desvalorização docente tem sido motivo de muitos potenciais profissionais procurarem outras profissões e formações fora do âmbito docente. Enquanto outros recorrem ao fenómeno da "turbo-docência»', aspeto que condiciona seu efetivo desempenho profissional e prejudica a (re)/construção da ldentidade Profissional cabendo-the a impossibilidade da sua participação no processo de ensino-aprendizagem.

Como já foi referenciado em Angola às funções da Profissão Docente deve ser acrescida um forte investimento na sua carreira, de modo a que este desenvolva as suas capacidades e competências, com o intuito de fortalecer a sua prática (RAUL, 2015).

\section{Valorização Docente na (re)construção da Identidade Profissional}

Estamos a viver um momento determinante da história da educação em que o mundo em que os professores realizam o seu trabalho está a sofrer alterações profundas e a composição demográfica do ensino está a mudar de forma dramática com o processo de reforma da classe de professores das décadas de 1960 a 1970, o ensino está de novo a tornar-se uma profissão de jovens (HARGREAVES, 2004, p. 15).

A valorização docente na (re)construção da identidade dos profissionais do Ensino Superior em Angola é uma necessidade que tem como repercussão o serviço docente. Portanto, já que trabalho é toda atividade humana que transforma a natureza a partir de uma certa matéria. Falar em trabalho docente é reconhecer o trabalho como cerne do desenvolvimento e de inclusão social, reconhecer o valor do trabalho como aspecto central na nossa sociedade, apresentar disposição para dirigir esforços a fim de consolidar as conquistas e mobilizar á sociedade para ir a busca de alternativas para esses desafios sociais (RAUL, 2015). O Estatuto da Carreira Docente do Ensino Superior de Angola (ANGOLA, 2018), artigo 34 $(c, d, f)$ relativamente aos Direitos dos Docentes define:

Ser avaliado, valorizado, reconhecido e remunerado justamente, de acordo com as suas habilitações académicas, técnicas e profissionais, bem como da qualidade do seu desempenho e dos 
resultados obtidos, nos termos da lei; Ser apoiado no processo de progressão da carreira docente, através de licenças, bolsas de estudo e outras formas de apoio no sentido de melhorar continuamente, a sua formação académica, científica e técnica e cultural, nos termos da lei; Ser tratado com respeito e justiça, dentro dos marcos da lei, no processo disciplinar de que seja parte (ANGOLA, 2018).

Os temas sobre a identidade profissional são de capital utilidade sobretudo quando não se trate de definir uma identidade fixa, mas, de compreender as múltiplas identidades que existem numa profissão e, sobretudo, de pensar a (re)construção identitária como um processo. Nesse sentido, ninguém constrói a sua identidade profissional fora de um contexto organizacional e de um posicionamento no seio de um coletivo que the dê sentido e densidade (DUBAR apud NÓVOA, 2017).

(Re)construir a indentidade profissional significa, também restabelecer o profissionalismo do professor, reconfigurar as características da sua profissão na procura de uma identidade pessoal e coletiva na instituição. È preciso também investir numa formação de qualidade, de modo que a profissão ganhe mais credibilidade e dignidade profissional (RAUL, 2015).

Nóvoa (2009), refere que a importância do desenvolvimento profissional a valorização do professor deve estimular uma perspectiva crítico-reflexiva, que forneça aos professores os meios de participação nas mesmas, para facilitam as dinâmicas da autoformação. pois, ser professor é compreender os sentidos da instituição escolar, integrar-se numa profissão, aprender com os colegas mais experientes.

O professor deve igualmente ser um eterno aprendente a (re)construção da sua identidade profissional. Por isso, falar da aprendizagem do professor é reportar a uma permanente (re)construção da sua profissão no seu exercício na Instituição de Ensino Superior a que pertence (RAUL, 2015).

Portanto, a participação de docentes quer na formação contínua e em todas atividades da sua prática profissional, fortalece o seu desenvolvimento pessol e profissional, quando há aceitação, reconhecimento em diferentes domínios quer a nível das políticas, traçadas pelo Estado, desde a sua materialização e ao nível das instituições e da sociedade no geral, o que contribui para valorização e a (re)construção da identidade profissional do docente. 
É preciso compreender que a formação contínua de docentes não se limita somente na frequência e obtenção de um título, académico, científico e profissional, ou simplesmente nas participações em seminários, cursos de agregação e superação pedagógica (CUTATELA, 2018).

Ela se desenvolve igualmente na prática diária do professor na escola, nas planificações, no trabalho colaborativo com os colegas, permitindo que este alcance níveis de elaveda qualidade educativa e profissional para a satisfação coletiva e pessoal. "A formação de professores está muito afastada da profissão docente, das suas rotinas e culturas profissionais" (NÓVOA, 2009, p. 11.

Assim, se nos rendermos à ideia de que a educação pública só pode ser um sistema de baixo custo assente em professores com baixas habilitações, mal pagos e sobrecarregados, cuja função consiste apenas em manter a ordem, ensinar para o teste e seguir os ditames do currículo estandardizado, então os professores para as próximas três décadas serão incapazes e desmotivados de ensinar para a sociedade do conhecimento, e para além dela (NÓVOA, 2009).

É necessário que os professores conversem entre si sobre a profissão e os conteúdos, troquem ideias e se preocupem sobre a forma como estão a conduzir as práticas profissionais e pedagógicas, pois só assim poderão detectar pontos positivos e negativos no que estão a fazer (RAUL, 2015).

Deve-se facilitar a troca de experiências entre os profissionais docentes, para se criar um ambiente propício para o desenvolvimento intelectual, estimulando-os a expor os seus saberes, a criticar e enriquecer as suas práticas através da pesquisa e das exigências dos seus colegas, da direção da escola e do Ministério do Ensino Superior, Ciência, Tecnologia e Inovação (RAUL, 2015).

Em alternativa, podemos promover um sistema educativo de alta capacidade, com grande investimento, no qual os professores altamente qualificados são capazes de gerar criatividade e engenho nos seus alunos, fruto da própria experiência de criatividade e flexibilidade na forma como são tratados os professores e se desenvolverem como profissionais da sociedade do conhecimento (HARGREAVES, 2004).

Para melhor compreender a qualidade da educação é preciso, antes de mais, melhorar o recrutamento, formação, estatuto social e condições de 
trabalho dos professores, pois estes só poderão responder ao que deles se espera se possuírem os conhecimentos e competências, as qualidades pessoais e profissionais e a motivação requerida (RAUL, 2015).

\section{Conclusões}

A partir da análise realizada sobre o processo de Valorização Docente no contexto angolano é possível concluir que a questão da (re)construção da identidade profissional do professor é atual e necessária em vários ambientes sociais, culturais e profissionais.

A Profissão Docente pela sua complexidade é marcada de contradições e necessidades de carácter político, social e económico, para tal é considerada como o processo pelo qual o professor adquire, desenvolve, vivencia e experimenta saberes e competências no contexto da sua atuação pedagógica. As dificuldades e insuficiências que condicionam a Valorização Docente referidas no presente texto por diferentes autores, nos documentos normativos e a vivências dos autores no contexto da Profissão Docente em Angola ilustram alguns fatores que inibem o seu desenvolvimento e a (re)construção da identidade profissional.

Os principais obstáculos identificados referentes aos níveis salariais baixos e à falta de atualização nas carreiras e categorias; falta de imparcialidade na seleção dos docentes para as formações contínuas; docentes com grau académico e categorias muito baixas; difíceis e precárias condições de trabalho; a burocratização e controlo pelos gestores do trabalho docente; falta de motivação, e vontade de participação em atividades académicas e científicas, estão na base da desvalorização da Profissão Docente, e condicionam a (re) construção da identidade profissional.

Há uma acentuada discrepância entre a realidade objetiva da Profissão Docente em Angola, as vivências dos seus participantes, e a análise dos discursos dos diferentes autores (NÓVOA, 1999; RAUL, 2015; BUZA; BUZA, 2015; SIMÕES, SAMBO, FERREIRA; FRESTA, 2016) entre outros, com as orientações expressas nos documentos normativos tais como o Estatuto da Carreira Docente do Ensino Superior (ANGOLA, 2018) artigo 34․, (c, d, f) sobre os «direitos dos docentes», os objetivos plasmados no Plano Nacional de Desenvolvimento, (20 18-2020), na Lei de Bases do Sistema de Educação e 
Ensino (ANGOLA, 2016 ) referidos no artigo $51^{\circ}$, alínea (c-d), e nas metas que se perspetivam no Plano Nacional de Formação de Quadros (201 2-2020), e enraizadas nos discursos, mais que não são materializadas dentro das políticas públicas e educativas traçadas para a melhoria da Profissão Docente e consequente (re)construção da identidade destes profissionais.

Para minimizar as dificuldades apontadas é necessário estabelecer políticas mais objetivas na formação inicial e contínua, que passam pela seleção de melhores candidatos para o ingresso na formação inicial e a participação em formações continuadas dos professores em exercício, apoiá-los com bolsas nacionais e internacionais que financiem a sua formação ao nível de cursos de Mestrado e Doutoramento. Para isso é importante delegar algum poder e autonomia as Instituições do Ensino Superior, para a descentralização de alguns serviços evitando deste modo, o excesso de burocratização no órgão de tutela (Ministério do Ensino Superior Ciência Tecnologia e Inovação) quanto a seleção desses profissionais.

Ministério do Ensino Superior Ciência Tecnologia e Inovação enquanto órgão competente pela formulação e implementação da Política para o ES deve apostar seriamente na formação dos quadros superiores e 18 assegurando-lhes uma sólida preparação científica, técnica, cultural e humana. Deve, coordenar harmoniosamente o funcionamento de todas as Instituições de Ensino Superior (respeitando, obviamente, os diferentes regimes de autonomia, conferidos por lei). Deve ainda, no âmbito do Plano Nacional de Formação de Quadros (PNFQ, 201 2-2020), executar o plano de Formação de Quadros Superiores e o plano de Formação e Capacitação de Professores e de Investigadores para o Ensino Superior e Sistema Nacional de Ciência, Tecnologia e Inovação.

Sabendo que a (re)construção da identidade da Profissão Docente depende igualmente da componente pessoal que é internalizada pelas posições sociais, representações individuais e significados que são atribuídos pela sociedade de outras instituições e do Estado em geral no seu quotidiano, é fundamental que as políticas públicas implementadas estejam viradas para a atração de quadros de alto nível, na promoção da estabilidade do corpo docente, através da atualização de subsídios, o progresso na carreira e o incentivo da sua participação pessoal e coletiva na comunidade através de projetos de extensão universitária. 
Os professores devem de igual modo, procurar durante a sua trajetória pessoal envolverem-se e implicarem-se na profissão, assumindo os seus papéis, cientes das suas responsabilidades, comprometendo-se com a profissão, e tomar consciência pessoal (ética, moral e sociall), autovalorizarem-se, trabalharem para os seus direitos e cumprirem com os seus deveres.

Na vertente profissional os professores devem participar no desenvolvimento institucional, através do seu envolvimento no coletivo de estudantes e de colegas de profissão, nos projetos educativos da instituição, em formações para o seu desenvolvimento profissional, contribuindo para a (re)construção da sua identidade profissional.

Angola, um país em vias de desenvolvimento que durante muito tempo enfrentou diversas dificuldades na afirmação das instituições educativas e sociais face a sua credibilização e aceitação por parte da sociedade, precisa de profissionais capazes de responderem a um novo rumo da formação de futuras gerações. Para isso a sociedade Angolana deve respeitar, prestigiar e apoiar as políiticas que são traçadas a favor dessa classe de profissionais.

\section{Notas}

1 Turbo-docência: Em Angola este termo é utilizado para aqueles docentes, que exercem a profissão em várias instituições de ensino e ou diferente daquela pelo qual ele exerce a atividade profissional.

\section{Referências}

ANGOLA. Decreto-Lei n 7/2009, de 12 de maio 2009. Estabelece a reorganização da rede das Instituições de Ensino Superior Públicas, a criação de novas Instituições do Ensino Superior e o redimensionamento da Universidade Agostinho Neto (UAN). Diário da República I-Série, 87, 2009.

ANGOLA. Decreto-Lei no 17/2016 de 7 de outubro de 2016. Aprova a Lei de Bases do Sistema de Educação e Ensino em Angola. Diário da República I - Série, 170, 2016.

ANGOLA. Decreto-Lei no 191/2018 de 8 de agosto de 2018. Aprova o Estatuto da Carreira Docente do Ensino Superior em Angola. Diário da República I-Série, 1 18, 2018. BUZA, Juliana Lando Canga; GONÇALVES, Terezinha Valentin Oliveira. Motivação ao magistério e identidade de professores que ensinam ciências em um país em reconstrução: 
Angola/Cabinda. 2007. Disponivél em: http://www.nutes.ufrij.br/abrapec. Acesso em: 15 fev. 2019.

BUZA, Juliana Lando Canga; BUZA, Alfredo Gabriel. Gestão do ensino superior em angola os desafios endógenos e exógenos. 2015. Disponível em: http://www.aforges.org/wp-content/. Acesso em: 27 fev. 2019.

CARDOSO, Ermelinda Monteiro Silva; FLORES, Maria Assunção. A formação incial de professores em Angola: problemas e dasafios. In: CONGRESSO INTERNACIONAL GALEGO-PORTUGUÊS DE PSICOPEDAGOGIA. 10. 2019. Actas [...] Braga: Universidade de Minho, 2009.

CARDOSO, Jorge Rio. O professor do futuro: valorizar os professores, melhorar a educação. Lisboa: Clube do Livro. 2013.

CASSULE, Abel da Costa; SIMÕES, Aníbal João Ribeiro. Representações sociais sobre a constrtução da identidade profissional docente: um caso do ISCED-Huambo. Revista Electrónica Formación y Calidad Educativa (REFCalE), Vicerrectorado Académico de la Universidad Laica Eloy Alfaro de Manabí, Ecuador, v. 6, n. 3, p. 203-214, set./dez. 2018.

CUTATELA, Arão Chilulo. A importância do trabalho colaborativo na formação contínua de docentes do Departamento de Ciências da Educação da Escola Superior Pedagógica do Bié. Revista Órbita Pedagógica, Isced-Huambo, v. 5, n. 3, p. 12-23, set./dez. 2018.

20 DAY, Christopher. Desenvolvimento profissional de professores: os desafios da aprendizagem permanente. Portugal: Porto Editora, 1999.

DETOMINI, Gabriela Mendes; MARIOTINI, Sérgio Donizeti. Fracasso no exercício do ofício docente: consequências da desvalorização social da profissão docente. Cadernos de Educação: Ensino e Sociedade, Bebedouro (São Paulo), v, 4, n. 1, p. 368-383, mar./jun. 2017.

ESTRELA, Maria Teresa. Profissão docente: dimensões afetivas e éticas. Portugal: AREAL Editores, 2010.

FORMOSINHO, João. A academização da da formação de professores. In: FORMASINHO, João. Formação de professores: aprendizagem profissional e acção docente. Porto: Porto Editora/LDA, 2009.

GALINDO, Wedna Cristina Marinho. A construção da Identidade profissional docente. Revista Psicologia Ciência e Profissão, Araraquara, v. 24, n. 2, p. 14-23, abr./ago. 2004. HARGREAVES, Any. Ser Professor na era da insegurança. In ÁUREA Adão e ÉDIO Martins (orgs). Os professores: identidades (re) reconstruidas. Lisboa: Edições Universitárias Lusófonas, 2004. 
IRMA-PANZO, Boaventura Joaquim. A extensão universitária em Angola. Tendências, acções e projeções. Angola: Luanda, 2018.

IZA, Dijnane Fernanda Vedovatto; BENITES, Larissa Cerignoni; SANCHES NETO, Luiz; CYRINO, Marina; Ananias, ELISANGELA Venâncio; ARNOSTI, Rebeca Possobom; SOUZA DE NETO, Samuel (Org.). Identidade docente: as várias faces da constituição do ser professor. Revista Eletrônica de Educação, v. 8, n. 2, p. 273-292, fev./abr. 2014.

JESUS, Saul Neves de. Motivação na Profissão docente: Perspetivas para o bem-estar docente. In ÁUREA Adão; ÉDIO Martinas (Org.). Professores: Identidades (re)construidas. Lisboa: Edições Universitárias Lusófonas, 2004.

KANDINGI, Adelina Alexandra Carlos Pio de. A expansão do ensino superior em Angola. (Um estudo sobre o Impacto das instituições de ensino superior privado). Tese (Doutorado em Educação) - Programa de Pós-Graduação em Educação, Universidade de Nova Lisboa, 2016.

LAWN, Martins. Os professores e a fabricação de identidades. In: ANTÓNIO Nóvoa; JURGEN Schriewer (Org.). A difusão mundial da escola. Lisboa: Educa. 2000.

MANUEL, Tuca. A regulação do ensino superior como interface da regra do funcionalismo público do Estatuto da Carreira Docente em Angola. 2016. Disponível em: http://www. aforges.org/wp-content/uploads/2016/11/15-Tuca-Manuel. Acesso em: 15 nov. 2018. MACHADO, Joaquim; FORMOSINHO, João. Professores, escola e formação. Políticas e práticas de formação contínua. In: FORMOSINHO João. A formação de professores: aprendizagem profissional e acção docente. Porto: Porto Editora, 2009.

MED. Reforma Educativa. Ministério da Educação de Angola. Luanda: Angola, 2010.

MELO, Daniela da Silva. Profissão docente: um estudo sobre a desvalorização/valorização da Carreira. In: JORNADA BAIANA DE PEDAGOGIA, 2; 2016. Anais [...]. Ihéus, 2016. Disponível em: http://www. Users/documents/profissao_docente_um_estudo_sobre_a.pdf. Acesso em: 5 nov. 2018.

MESCTI. Acta do $2^{\circ}$ Conselho Nacional do Ensino Superior, Ciência Tecnologia e Inovação. Conselho Nacional. Luanda: Angola, 2018a.

MESQUITA, Elza da Conceição. Formação inicial, profissão docente e competências para a docência: a visão dos futuros professores. Revista de Educação, EDUSER, Instituto Politécnico de Bragança - Escola Superior de Educação, v. 2, n 1, p. 3-19, Bragança, Portugal. 2010. Disponível em: http://www.eduser.ipb.pt. Acesso em: 18 out. 2018.

MOREIRA, Justina. Portefólio do professor: o prortefólio reflexivo no desenvolvimento profissional. Porto: Porto Editora, 2010. 
NÓVOA, António. Para uma formação de professores construída dentro da profissão. Lisboa. Portugal: Universidad de Lisboa, 1999.

NÓVOA, António. Professores: Imagens do futuro presente. Lisboa: Educa, 2009.

NÓVOA, António. Firmar a posição como professor, afirmar a profissão docente. Cadernos de Pesquisa, São Paulo SP Brasil, v, 47 n. 166, p. 11 106-1 133, out./dez. 2017.

PND. Plano Nacional de Desenvolvimento (2018-2020). Luanda: Angola, 2018.

PNFQ. Plano Nacional de Formação de Quadros (2012-2020). Luanda: Angola, 2012.

RAUL, Rosa Manuel. A construção da identidade profissional dos professores: o caso da escola n 2055 do município da Maianga. 2015. Dissertação. (Mestrado em Administração e Gestão Educacional) - Programa de Pós-Graduação, Universidade de Évora, 2015.

ROLDÃO, Maria dos Céu. Função docente: natureza e construção do conhecimento profissional. Revista Brasileira de Educação, Minho, v. 12, n. 34, p. 94-108, jan./abr. 2007.

SILVA, Rosa; SILVA, António Carvalho da. Um olhar sobre a formação de professores em Angola. In: COLÓQUIO CABO-VERDIANO DE EDUCAÇÃO - CEDU. 2; 2015 . Anais [...]. Praia: Cabo- Verde: Edições Uni-CV, 2015.

SIMÕES, Cristovão; SAMBO, Maria do Rosário; FERREIRA, Albano; FRESTA, Mário (Org.). Ensino superior em Angola: desafios e oportunidades ao nível institucional. Revista FORGES

22 - Fórum da Gestão do Ensino Superior nos Países e Regiões de Língua Portuguesa. Forges, v. 3, n. 1, p. 79-102, 2016.

TEIXEIRA, Inês; BATISTA, Paula; GRAÇA, Amândio. A reconstrução da identidade profissional em comunidades de prática. In: CORREIA, Luís Grosso; POÇAS, Ruth Leão Sara (Org.). 0 tempo dos professores. Porto: Universidade do Porto, 2017.

TEODORO, António. Um estudo europeu sobre os professores. Atratividade, perfil e conteúdo ocupacional da profissão docente. In: ÁUREA Adão; ÉDIO. Martins. Os professores: identidades (re) construídas. Lisboa: Edições Universitárias Lusófonas, 2004.

VARGAS, Jamily Charão. Refletindo sobre a obra "Profissão Professor": contribuições de Antônio Nóvoa. Revista Partes: P@rtes (São Paulo- Brasil) www.partes.com.br/educacao. asp Acesso aos 1 de Outubro de 2018, 2008. 
MS. Arão Chilulo Cutatela Doutorando pelo Instituto de Educação da Universidade de Lisboa (Lisboa) Professor Auxiliar da Escola Superior Pedagógica do Bié (Angola) Jovens Investigadores do Instituto de Educação da Universidade de Lisboa ORCID : https:/ / orcid.org/0000-000 1-8279-5668 E-mail: lourelulu@yahoo.com.br e cutatela@gmail.com

Prof. Dr. Alfredo Maria de Jesus Paulo Universidade José Henrique Varona/Havana (Cuba) Escola Superior Pedagógica do Bié (Angola) Professor Catedrático e Investigador pelo ISCED-HUAMBO (Angola) Instituto Superior de Educação do Huambo-Angola ORICID : https://orcid.org/0000-0003-4545-8886 E-mail: pickmaria07@gmail.com

Prof. Dr. Luís Alexandre da Fonseca Tinoca University of Texas at Austin (Estados Unidos) Universidade de Lisboa (Portugal) Professor e Investigador Unidade de Investigação e Desenvolvimento em Educação e Formação Instituto de Educação, Universidade de Lisboa (Portugal) Universidade de Lisboa ORCID : https:/ / orcid.org/0000-000 1-6950-3245 E-mail: Itinoca@ie.ulisboa.pt Recebido 12 set. 2019 Aceito 17 nov. 2019 